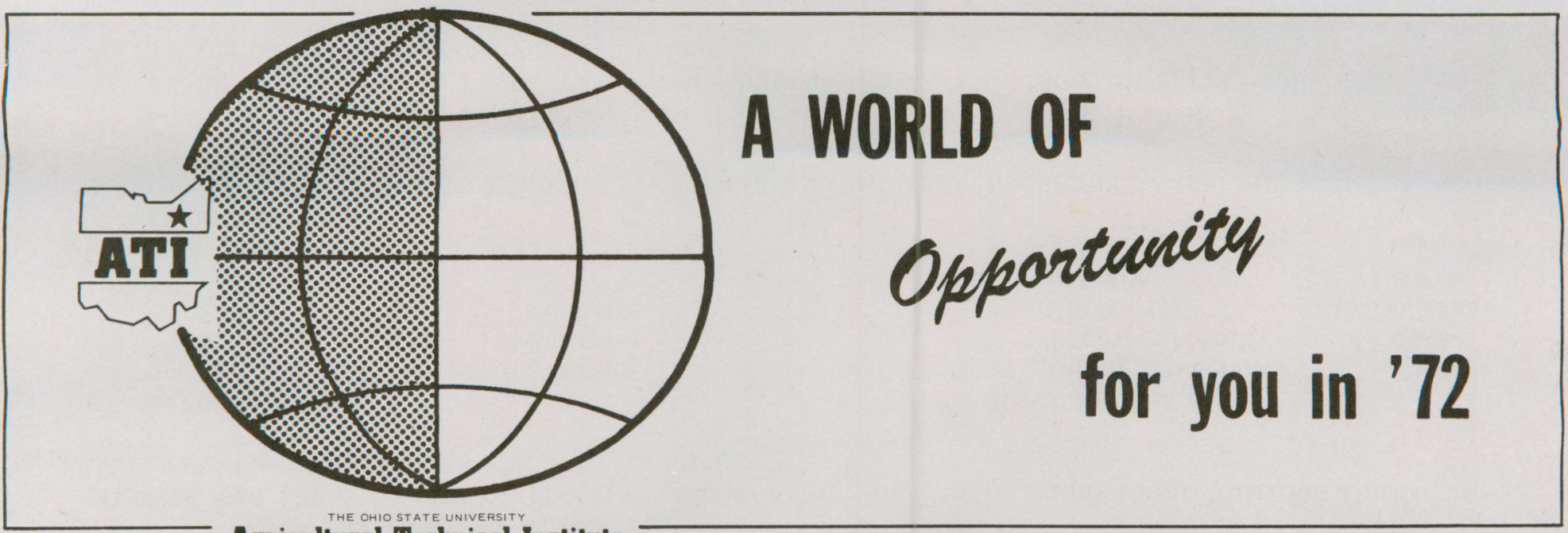

Agricultural Technical Institute 


\section{SOIL FERTILITY AND PLANT NUTRITION}

Attempt is made in this field of study to qualify the technician in specialized areas of soil fertility and plant nutrition, crop production, and agricultural business. Soil fertility and plant nutrition is stressed because of the necessity for technicians to be able to make practical applications of scientific knowledge under field conditions. Crop production is stressed so that the student understands specific technical and cultural practices affecting crop production. Business and management is stressed because of the commercial setting within which most technicians perform their work.

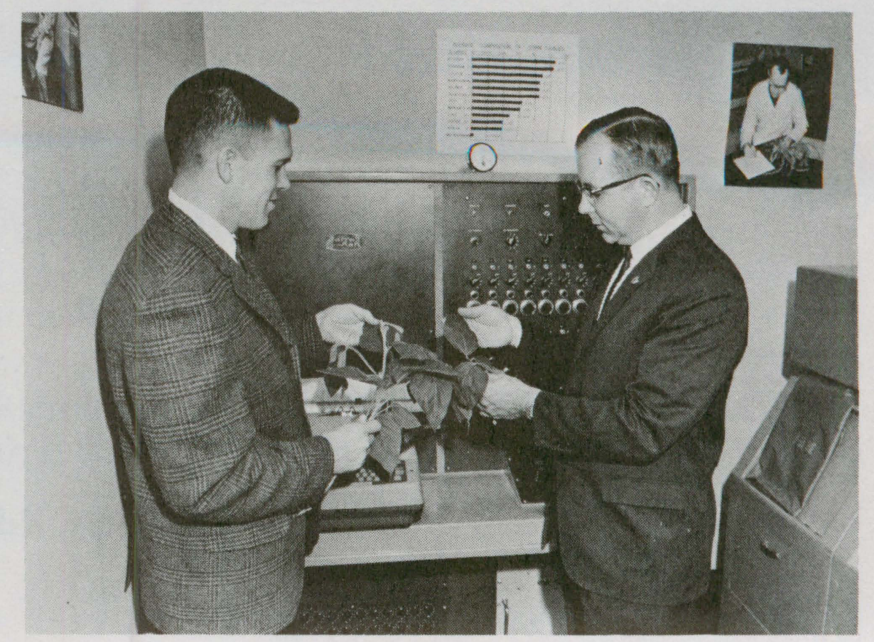

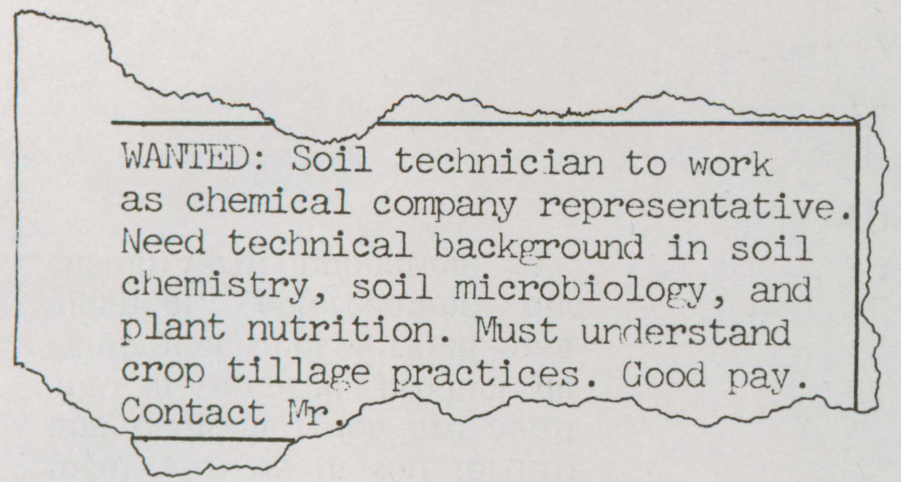

The soil and fertilizer industry is rapidly expanding. Farmers are relying more and more on scientific methods to determine fertility needs on their farms. They depend upon representatives of fertilizer manufacturers and distributors to make soil and plant analyses and recommend proper amounts and types of commerical fertilizers. Persons with technical knowledge capable of making these recommendations are in extremely short supply.

\section{PLANT SCIENCES TECHNOLOGY}




\section{JOBS}

Career opportunities for technical workers in soil fertility and plant nutrition are available in research, product development, sales, service, management, enforcement and custom farm application.

\section{CAREER OPPORTUNITIES}

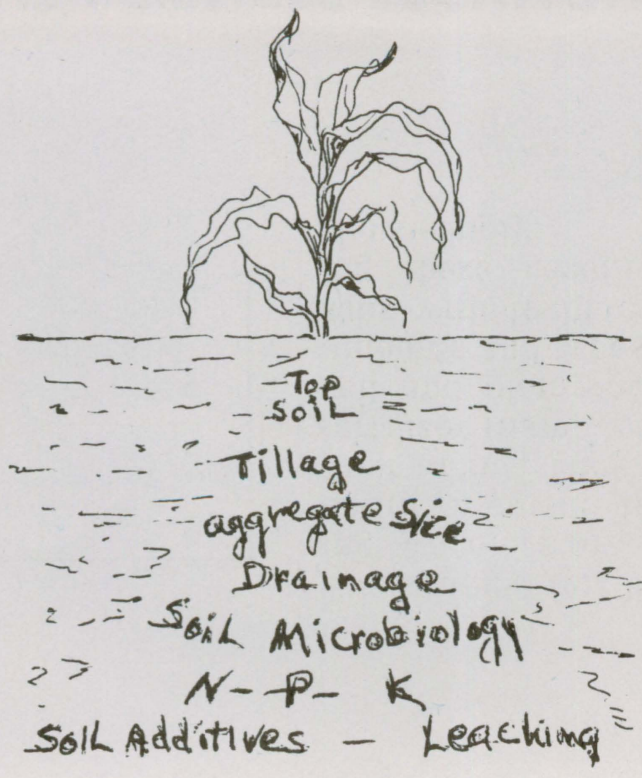

\section{JOB TITLES}

Technicians in this field of specialization include:

Field Service Representative

Soils Technician

Farmer Manager or Operator

Land Use Analyst

Research Assistant

Soils Specialist 


\section{ACADEMIC PROGRAM}

CURRICULUM-Reflecting the standards prescribed by the Ohio Board of Regents, the curriculum for the Soil Fertility and Plant Nutrition Option includes the following major areas of course work and the approximate proportion of time allocated in total credit hours for each area:

I. General Studies-Including oral and written communications, and

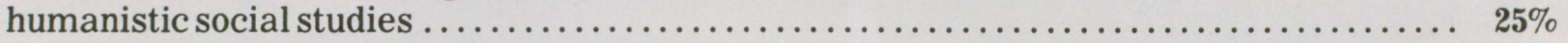

II. Basic Studies-Subjects basic to the study of agriculture including physical and biological sciences and mathematics.

III. Technical Studies-Including supporting technical studies and specialized technical studies

COURSES AND AREAS OF STUDY-The curriculum in the Soil Fertility and Plant Nutrition Option includes the following courses and areas of study:

General Studies

Communications

Social Sciences

Elective

$$
\begin{aligned}
& 3 \text { Courses } \\
& 4 \text { Courses } \\
& 1 \text { Course }
\end{aligned}
$$

\author{
Basic Studies \\ BiologicalScience \\ Technical Math \\ Chemistry \\ Elective
}

\section{Course \\ 1 Course \\ 2 Courses}

1 Course

Technical Studies

Supporting Technical Studies-Agricultural Business, Biochemistry and Agricultural Mechanics.

Specialized Technical Studies-Soil Science, Entomology, Plant Pathology, Weed Science, Soil Management, Fertilizers, Plant Analysis, Crop Production, Surveying Soils, Soil Testing, and Plant Anatomy and Physiology. 
EARN-LEARN OCCUPATIONAL INTERNSHIP-A requirement in this curriculum is the completion of at least one quarter in an Earn/Learn Occupational Internship. Students are placed on jobs which require Soil Fertility and Plant Nutrition skills. The length of the internship and the term during which it occurs will vary according to the program of the student. The internship is an integral part of the instructional program; the student pays fees, enrolls for credit, meets course requirements, receives grades, is supervised by Institute personnel, and is paid a salary as an employee of the firm.

\section{ADMISSION TO THE INSTITUTE AND ADDITIONAL INFORMATION-}

Procedure-Admissions forms may be obtained from the Agricultural Technical Institute, Admissions Office, Wooster, Ohio 44691. Information regarding requests for transcripts of credit, medical examination report, interview appointments and fee payments will be mailed with these forms.

Applications for admission to the Agricultural Technical Institute must be submitted on or before: July 15 for the Autumn quarter, November 1 for the Winter quarter, February 1 for the Spring quarter and May 1 for the Summer quarter. All curriculums will have limited enrollments and each will be filled according to date application is received. 


\section{Agricultural Technical Institute}

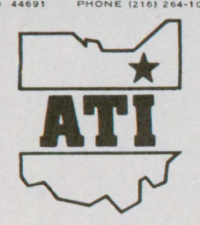

